\title{
Examining the Method of Proofs and Refutations in Pre-Service Teachers Education
}

\section{Examinando o Método de Provas e refutações na Educação de Professores Pré-serviço}

Fatih Karakuş*

Mesut Bütün**

\begin{abstract}
There is some evidence in the mathematics education literature that Lakatos' proofs and refutation methods can be useful to examining students' conjecture production and proof construction process. The purpose of this study was to determine how the Lakatos method goes and which steps of the method works in the teacher education program. The population sample for this study consists of 24 senior pre-service teachers in elementary mathematics education in Turkey (16 women and 8 men). Pre-service teachers were given a problem in which they examined the relation between perimeter and area of a rectangle. Data was collected with a camera, field notes, and groups' written solutions and analyzed on the basis of framework included in Larsen and Zandieh's (2008) study. The finding revealed that Lakatos' method was usable in the teacher education program. But some steps of the method described in Lakatos' (1976) historical case study were not provided in the real classroom environment.

Keywords: Philosophy of Mathematics. The Method of Proofs and Refutations. Preservice Teacher Education.

\footnotetext{
* PhD in Mathematics Education at Karadeniz Teknik University in Trabzon, Turkey. Professor in the Department of Elementary Mathematics Education at Education Faculty in Afyon Kocatepe University. Adress: Afyon Kocatepe University Egitim Fakultesi, Ahmet Necdet Sezer Kampusü Gazligöl Yolu, 03200, Afyonkarahisar. E-mail: fkarakus@aku.edu.tr

** PhD in Mathematics Education at Karadeniz Teknik University in Trabzon, Turkey. Professor in the Department of Secondary Science and Mathematics Education at Education Faculty in Cumhuriyet University. Adress: Cumhuriyet Üniversitesi, Egitim Fakultesi, 58140, Kampüs, Sivas. E-mail: mbutun@cumhuriyet.edu.tr
} 


\section{Resumo}

Há algumas evidências na literatura em educação matemática que o método de provas e refutações de Lakatos pode ser útil para examinar a produção de conjecturas e o processo de construção de provas dos estudantes. O objetivo deste estudo foi determinar a forma como o método de Lakatos funciona e quais passos do método trabalhar no programa de formação de professores. A amostra da população para este estudo consiste de 24 professores em formação pré-serviço de educação matemática elementar da Turquia (16 mulheres e 8 homens). Os professores pré-serviço receberam um problema em que examinaram a relação entre perímetro e área de um retângulo. Os dados foram coletados com uma câmera, notas de campo e soluções escritas dos grupos de alunos e analisados com base no quadro desenvolvido no estudo de Larsen e Zandieh (2008). A análise dos dados revelou que o método de Lakatos era utilizável no programa de formação de professores. Porém, alguns passos do método descrito no estudo de caso histórico de Lakatos (1976) não foram produzidos no ambiente real de sala de aula.

Palavras-chave: Filosofia da Matemática. O Método de Provas e Refutações. Formação de Professores Pré-serviço.

\section{Introduction}

The philosophical position and epistemology of mathematics always has a major effect on mathematics teaching (STEINER, 1987). While there is not a direct relationship between the philosophy of mathematics and mathematics education, different philosophies of mathematics have very different results in mathematics education (ERNEST, 1991). In this context, it is very difficult to think that mathematics education can be separated from its philosophy. Thom emphasizes the relationship between the philosophy of mathematics and mathematics education as "in fact, whether one wishes it or not, all mathematical pedagogy, even if scarcely coherent, rests on a philosophy of mathematics" (THOM, 1973, p. 204). Toumasis (1997) explained in his paper, which compares the NCTM standards and the philosophy of mathematics, that mathematics curriculums adopt two different philosophical views: "absolutist" and "fallibilist". Moreover, he pointed out that the NCTM standards are based on the fallibilist view. Lakatos (1976), one of the important followers of the fallibilist philosophy of mathematics, presented a method for the formation process of mathematical knowledge in his book "Proofs and Refutations" (REICHEL, 2002). In that book, he indirectly changed traditional views in mathematics teaching This means that mathematics should not be taught as a set of unchanging absolute 
truths and as a matter of structured sets of axioms, but it should start with problems, conjectures and strategies. So, proofs and refutations influenced the theory and practice of mathematics education (REICHEL, 2002). Lakatos clarified in his method that mathematical knowledge develops and changes as a result of the conjecture-proofs-refutations process. Additionally, his method provides an exciting strategy for engaging students in mathematical problem solving and creating an environment in which students reason mathematically, communicate mathematically, and make mathematical connections (ATKINS, 1997). Parallel with this thinking, few studies have used Lakatos' method in the teaching and learning of mathematics (ATKÝNS, 1997; SRIRAMAN, 2006; LARSEN; ZANDIEH, 2008; SWINYARD; LARSEN, 2010; FUJITA et al., 2011). In this context, determining how the Lakatos method functions and which steps of the method work can provide us with important clues about the its validity for the teaching and learning of mathematics. Moreover, in an environment prepared in Lakatos' method, students perform different mathematical experiments in the process of conjecture-proofs-refutations, and their reactions to this method are also exhibited.

\subsection{The method of "proof and refutations" described by Lakatos}

Lakatos" "Proofs and Refutations" consists of dialogues in an imaginary classroom. In his book, Lakatos provides us with the historical development of arguments surrounding Euler -Descartes conjecture which is about the relationship between the number of vertices $\mathrm{V}$, sides $\mathrm{E}$ and faces $\mathrm{F}$ in a polyhedron: $\mathrm{V}-\mathrm{E}+\mathrm{F}=2$, in the form of a dialogue between students and a teacher. The teacher initially provides the class with a "proof" of Euler's conjecture and then the discussion starts. After the proof, students attempt to refute the teacher's original proof; counterexamples are provided by a number of students. As a result of counterexamples, the theorem is changed and the proof is corrected. The new counterexamples bring the new arrangements of the proofs or conjectures. In other words, if we begin with a conjecture or a problem, the search for a proof and counterexample increases at the same time. The new proofs explain the old counterexamples; the new counterexamples refute the old proofs. In that process, Lakatos defines counter-examples rejecting main conjecture as "global counter-examples." He also describes "local counterexamples" which deny the specific lemmas or the constructions which were used in the proof without targeting the main conjecture itself (LAKATOS, 
1976, p. 10-11). Davis and Hersh (1980, p. 292) summarized Lakatos' method as follows (see Figure1).

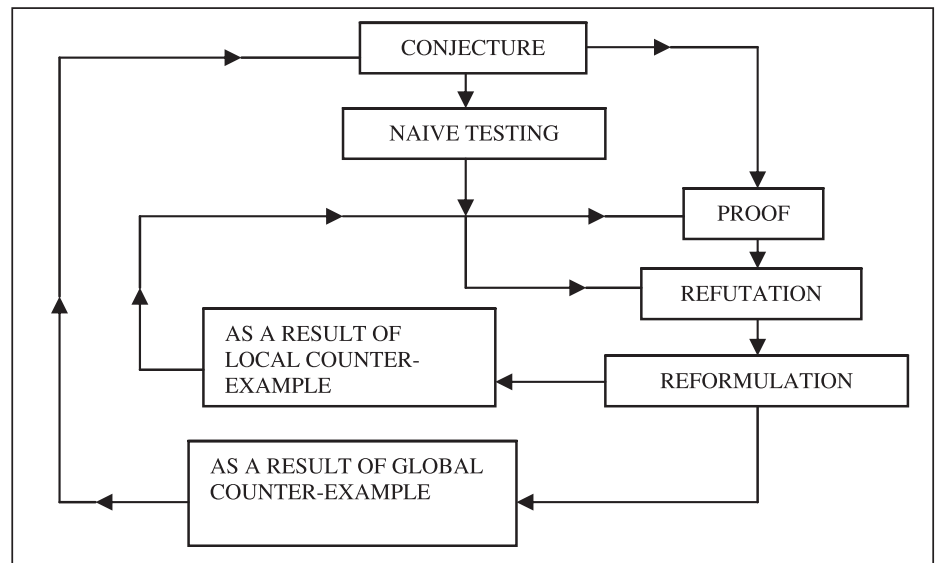

Figure 1 - Lakatos' method summarized by Davis and Hersh (1980, p. 292)

In summary, Lakatos' (1976) method of proofs and refutations consists of the following phases:

- Primitive conjecture;

- Proof (a rough thought-experiment or argument, decomposing the primitive conjecture into sub-conjectures);

- Global counter-examples emerge (counter to the primitive conjecture);

- Proof is re-examined as a new theorem or improved conjecture emerges.

\subsection{Literature review}

In the literature, especially in recent years, some researchers have tried to establish a relationship between Lakatos' method and mathematics education and to reflect on the implications of applying this method in the classroom. For example, in her study about the concept of angle and how to measure it, Atkins (1997) applied Lakatos' method in her classroom. In the study, students began by answering the question "what kind of angle is it?" and then continued the discussion by suggesting counterexamples to the answers mentioned in the classroom. At the end of the lesson, they arrived at a conclusion on which whole class agreed. To sum up, students tried to form their knowledge about the concept of angle and different kinds of angles themselves. 
Sriraman (2006) claims that one of the global aims of mathematics teachers is to show students the connections of mathematics subjects. In this respect, preparing the environment based on conjecture-proof-refutation, which Lakatos called "thought experiment," can help the teacher to implement this global aim. For this aim, Sriraman (2006) gave his students the opportunity to solve a different counting problem, and he tried to reflect his students' rich mathematical experiences during the classroom discussion guided by Lakatos' method. In this way, he tried to show that the students can learn counting problems in a classroom environment without the help of a book.

Larsen and Zandieh (2008) reshaped Lakatos' method within a realistic mathematics education ${ }^{1}$ and examined it in terms of its usage as proof for teaching and learning. They carried out a study with university students in a classroom similar to Lakatos' environment during algebra lesson. At the end of the study, Larsen and Zandieh (2008) concluded that Lakatos' method is a useful system for the classroom environment in which students can actively participate by improving their mathematics thinking. Also, mathematics learning can be encouraged in this environment with the conjecture-proof-refutation process.

Swinyard and Larsen (2010) used Larsen and Zandieh's (2008) framework during the study of the limit concept for undergraduate students as a design heuristic. They focused on students' definitions, counter-examples and the process for the formation of the limit concept.

Fujita et al. (2011) focused the relationship between conjecture, refutation and proof. They give some examples of students' activities dealing with 3D geometry problems by following Larsen and Zandieh's (2008) modal.

\subsection{The purpose and research question of the study}

There is some evidence in the mathematics education literature that Lakatos' proofs and refutation methods can be useful for examining students' conjecture production and proof construction process. Moreover, Larsen and Zandieh (2008) showed that Lakatos' framework can serve as a heuristic for designing instruction. For that reason, the aim of this study is to examine the discussion of pre-service teachers for a conjecture in an environment which is formed on the basis of Lakatos' method. In this context, the problems of this

\footnotetext{
${ }^{1}$ Realistic mathematics education (RME) is an approach determined by Freudenthal's view on mathematics (FREUDENTHAL, 1973) that mathematics must be connected to the real world and it must be considered g as human activity. (GRAVEMEIJER, 1994). According to the mathematics as human activity, students can obtain an opportunity to experience a similar process such as the process by which mathematical knowledge was invented.
} 
research are:

- How does the Lakatos method work?

- What happens during the stages of the Lakatos method?

\section{Methodology}

\subsection{Sample}

The population sample for this study consists of 24 senior pre-service teachers (16 women and 8 men) in elementary mathematics education in Turkey. Those pre-service teachers had no previous experience with Lakatos' method.

\subsection{Course and procedure}

The study was carried out the special teaching method course. Senior students can attend this course and it is a 14 week teacher education program in Turkey. Within this course, methods and strategies for teaching mathematics in grade 6- 8 are defined for pre-service teachers, and they are given the opportunity to put some of the strategies into practice.

In this study, the usefulness of Lakatos' method in the mathematics teacher education program was tested. Pre-service teachers were given a problem in which they examined the relation between perimeter and area of a rectangle. In Ma's (1999) study it was stated that due to the lack of knowledge and misconceptions with the teachers' content and pedagogical content knowledge, they usually think that if perimeter of rectangle increases the area of the same rectangle always increases, too. The main focus in this paper is preservice teachers' mathematical activities and discussions about the following problem: If a rectangle's perimeter increases, then does the area of the same rectangle always increase at the same time?

Pre-service teachers divided into eight groups and the study took place during two fifty-minute lesson periods. The teacher initiated the discussion, by putting forward the conjecture. The groups studied conjecture individually for twenty minutes and then the teacher led a discussion about the findings of the groups. The first name of this study was the teacher; the other took the field notes during the study.

Before the classroom discussion, it was identified that four of the groups $(1,4,5$ and 6$)$ determined that the conjecture was always true by using some 
special examples and algebraic proofs. The other four groups found counterexamples and concluded that the conjecture was not always true. Of the latter four groups, groups 2 and 8 changed and improved the conjecture by considering counter-examples and created a new conjecture which was always true. On the other hand, groups 3 and 7 found only counter-examples for the conjecture but did not improve it.

\subsection{Data collection}

Data was collected with a camera and field notes taken by the second author. Moreover, groups' written solutions, explanations and proofs were collected. During small group activities, the second author walked around the groups and tried to identify what they were doing. During whole class discussion, the camera focused on the whole classroom.

\subsection{Data analysis}

The aim of this study is to examine the mathematical discussions of preservice teachers about perimeter and area of a rectangle in terms of Lakatos' proofs and refutation method. In this context, the data was examined using a framework included in Larsen and Zandieh's (2008) study.

Larsen and Zandieh categorized Lakatos' "proofs and refutation" method in terms of the students' responses during a mathematical activity as follows (LARSEN; ZANDIEH, 2008, p. 208):

- Monster-barring: any response in which the counter-example is rejected on the grounds that is not a true instance of the relevant concept;

- Exception-barring: any response that results in a modification of the conjecture to exclude a counter-example without references for a proof;

-Proofs-analysis: the resulting modification to the conjecture is intended to make the proof work rather than simply exclude the counterexample from the domain of the conjecture.

In the proofs and refutation process, we primarily focused on the preservice teachers' responses and the outcome of their activities, like Larsen and Zandieh (2008). In particular, we analyzed whether the pre-service teachers' responses focused on the counter-examples, definitions, the conjecture or the 
proof, and whether the pre-service teachers' activity results in a modification to a definition or to the conjecture. Table 1 summarizes Larsen and Zandieh's (2008) framework for the method of proofs and refutations.

Table 1 - Larsen and Zandieh's (2008) framework for the method of proofs and refutations described by Lakatos (1976)

\begin{tabular}{lll}
\hline Type of activity & Focus of activity & Outcome of activity \\
\hline Monster-barring & $\begin{array}{l}\text { Counter-example \& underlying } \\
\text { definitions }\end{array}$ & $\begin{array}{l}\text { Modification or clarification of an } \\
\text { underlying definition }\end{array}$ \\
$\begin{array}{l}\text { Exception-barring } \\
\text { Proof-analysis }\end{array}$ & $\begin{array}{l}\text { The proof, the counter-example \& } \\
\text { the conjecture }\end{array}$ & $\begin{array}{l}\text { Modification of the conjecture } \\
\text { Modification of the conjecture \& } \\
\text { sometimes a definition for a new } \\
\text { proof-generated concept }\end{array}$ \\
\hline
\end{tabular}

\section{Results}

In this section, discussion of results of the pre-service teachers' work in groups was included. Thus, the situations of changing and improving the conjecture according to Lakatos' method are presented. In the classroom discussion, groups were named $\mathrm{G} 1, \mathrm{G} 2$, etc. and the researcher is referred to as A1.

\section{Primitive conjecture}

A1: Our conjecture was "if the perimeter of a rectangle increases, the area always increases too." What are your opinions on the validity of this conjecture? After working separately, groups discussed their proofs, conjectures and examples in the classroom discussion.

\section{Proof}

G1: If we increase two sides of a rectangle at the same time, area increases with perimeter. 


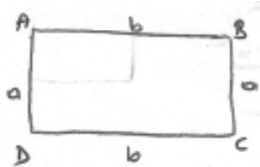

(1)

$\Rightarrow$ Cevie $=2(a+b)$

Alan $_{1}=a b$

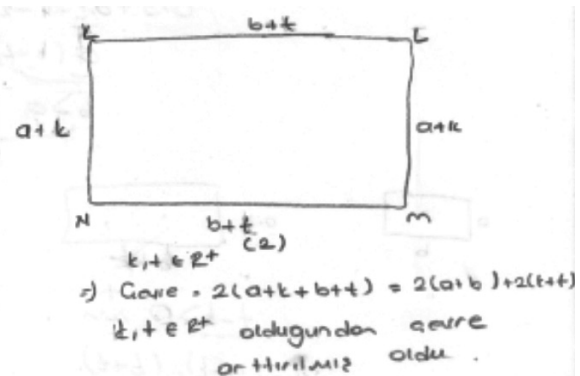

Alan $=(b+t) \cdot(a+k)$

$=a b+\underbrace{b t}_{k, t \in R+a t+t k}$

o halde:

$A_{\operatorname{lon} 2}>A_{\operatorname{lon} 1}$

Figure 2 - The proof of G1

G6: If we keep fixed one of the lengths of an side and increase the other one, the area always increases.

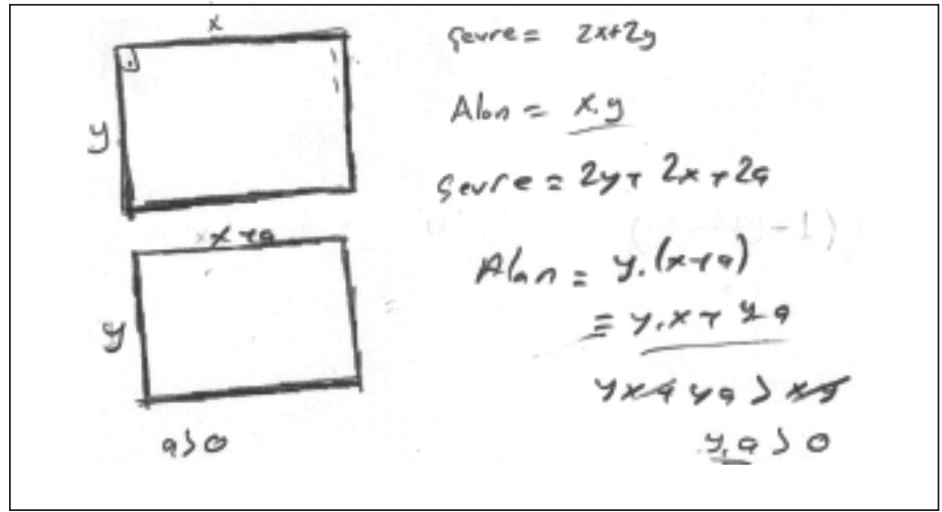

Figure 3 - The proof of G6

A1: Are there any cases in which while the perimeter increases, the area increases as well?

G1: If we increase the length of sides at the same proportion, the area increases as well, yet our proof includes this case.

G1 and G6 tried to confirm the conjecture and they proved that the conjecture is true for the following cases: 
First case: If we increase both sides of a rectangle (at the same or different ratio), the area increases with perimeter.

Second case: If we keep side fixed (width or length) and increase the other one, the area increases with perimeter.

The emergences of global counter-examples

G2: We found an example that if the perimeter increases, the area decreases. This example shows that the conjecture is not always true. For example, if the width of a rectangle is $7 \mathrm{~cm}$, the length is $8 \mathrm{~cm}$ and its perimeter is $30 \mathrm{~cm}$, its area is $56 \mathrm{~cm}^{2}$. Now, if we increase the length $3 \mathrm{~cm}$ to $11 \mathrm{~cm}$ and decrease the width $2 \mathrm{~cm}$, so we have width $5 \mathrm{~cm}$, the perimeter is $32 \mathrm{~cm}$ and the area is $55 \mathrm{~cm}^{2}$.

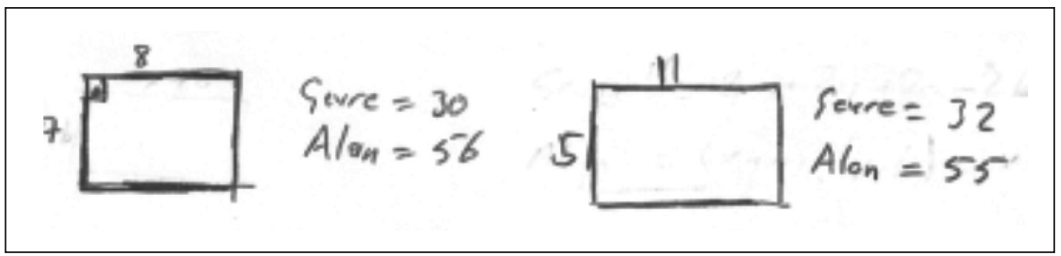

Figure 4 - The counter-example of G2

G7: We found another example when the perimeter increases but the area does not increase. That is, if the perimeter increases, the area can increase, reduce or as in our example it can remain the same.

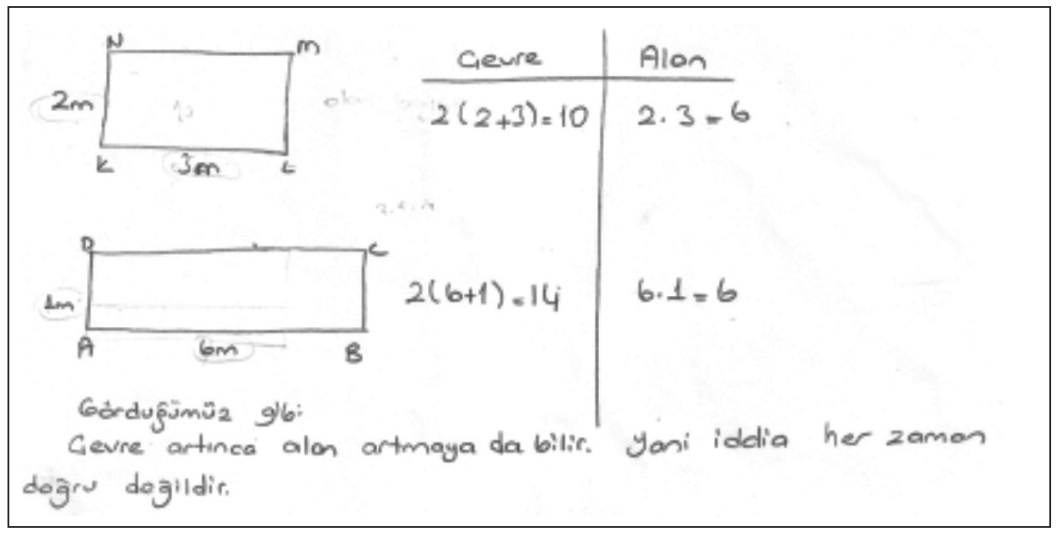

Figure 5 - The counter-example of $\mathrm{G}^{2}$

\footnotetext{
2 "Çevre" means "Perimeter" and "Alan" means "Area". The translation of the descriptive sentence in Figure 5 is "As we have seen the perimeter increases, the area may not increase. That is, the conjecture is not always true."
} 
G2 and G7 suggested two different counter-examples. Their counter-examples are global counter-examples, because they are directly intended for the conjecture and they do not examine the proof. It is observed that the pre-service teachers are surprised at this counter example and they believed that the conjecture is not true.

\section{Monster-barring}

A1: G2 and G7 put forward two crucial counter-examples that shake the accuracy of the conjecture. Now, is our conjecture collapsed completely? For example, according to the G1and G6, our conjecture is true. I guess it seems there is no rejection Yet, whenever we decrease one of the sides, in this case despite the increased perimeter, the area reduces or does not change. So, when is our conjecture true?

G8: Our conjecture is true when we increase the length of the sides or when we increase them while keeping one of them fixed. We cannot guarantee it in other cases.

The conjecture of G8 as "if we increase all lengths of sides, its perimeter increases as does the area" limits the conjecture and at the same time it locks out all counter-examples. We categorized this response as monster-barring because the focus was on the counterexamples and students did not modify the conjecture.

After this process, it is observed that some pre-service teachers accepted the accuracy of the conjecture apart from these counter-examples; they did not try to improve the conjecture anymore. Yet, after the example given by A1 teacher, some pre-service teachers tried to change the conjecture by considering counter-examples. So, it becomes a transition to exception-barring.

\section{Exception-barring}

A1: We had a conclusion that satisfied us when we exclude counter-examples and rearrange it in accordance with G1 and G6 proofs. But, I have an example in which, when the length of one side increases and the other one decreases, the area increases. Take a rectangle with width $4 \mathrm{~cm}$ and length $8 \mathrm{~cm}$. If the length is reduced $1 \mathrm{~cm}$, and width increased $2 \mathrm{~cm}$, the perimeter changes from $24 \mathrm{~cm}$ to $26 \mathrm{~cm}$, and the area increases from $32 \mathrm{~cm}^{2}$ to $42 \mathrm{~cm}^{2}$.

G7: There are some cases in which it is not true. So, this is not an exact answer. A1: Yes, but in some cases it is true. So, when is the conjecture true for these cases? 
After 3-5 minutes, G2 explained their proof.

G2: For this case we have such a proof. If we increase one of the sides as " $n$ ", and reduce the other one as " $n-1$ ", the area always decreases.

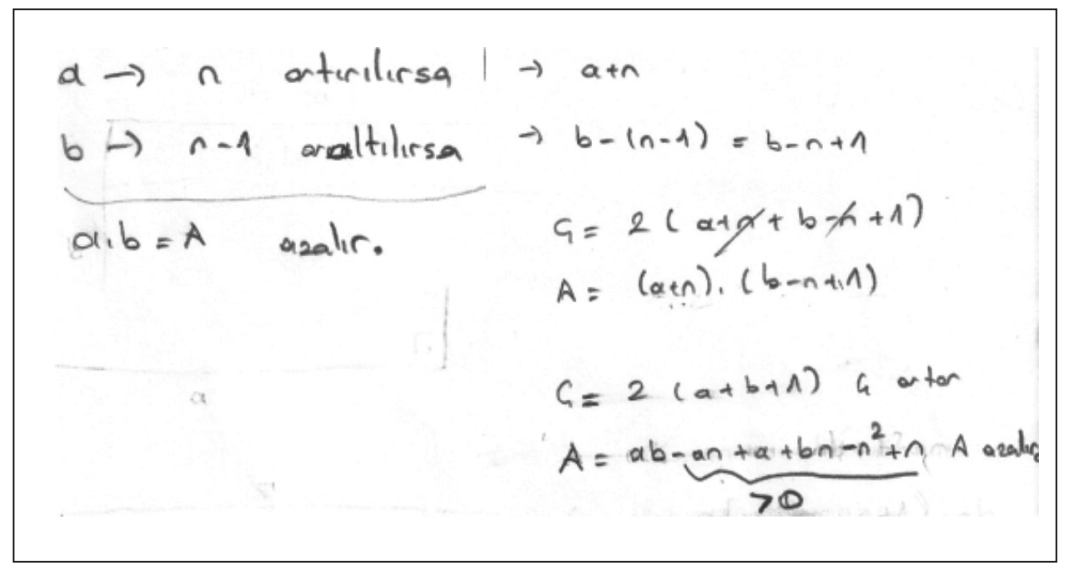

Figure 6 - Proof of G2

A1: My example refutes the proof of G2. In the example I reduce the length 1 $\mathrm{cm}$ and increase the width $2 \mathrm{~cm}$.

G8: We rearranged the proof of G2 as follows: "If the number added to the longer side is greater than the number removed from the shorter side, the area always increases when the perimeter increases.

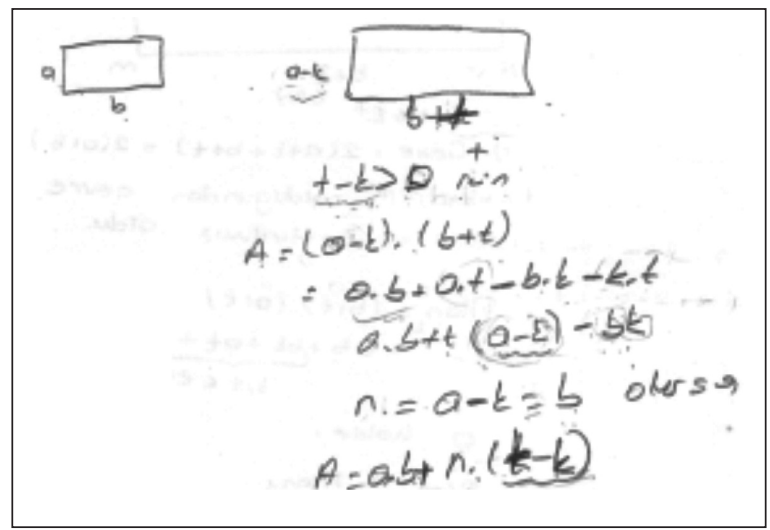

Figure 7 - Proof of G8

G7: In your proof you do not use the difference is more than 1. Moreover, we discovered that your proof is also incorrect. For a rectangle measuring $3 \mathrm{~cm} \mathrm{x}$ 
$5 \mathrm{~cm}$, let's remove $2 \mathrm{~cm}$ from the shorter side and add $4 \mathrm{~cm}$ to the longer one. So the rate of increase is $2 \mathrm{~cm}$. Yet, at the beginning, the area was $15 \mathrm{~cm}^{2}$, but in the end it becomes $9 \mathrm{~cm}^{2}$.

In this case G2 and G8 tried to improve the conjecture by considering the counter-examples; they did not exclude them. So, pre-service teachers focused only on the conjecture and counter-examples. For that reason, it is the result of exception-barring and not proof analysis, because the focus of their activities is only on conjecture and counter-examples and the proof is not perfect, yet.

\section{An improved conjecture is produced}

G2: I guess we have solved the problem. Take a rectangle with side lengths "a" and " $b$ ". If we increase one length and decrease the other, the area of the new rectangle is $\mathrm{A}=(\mathrm{a}-\mathrm{x})(\mathrm{b}+\mathrm{y})$. In order to have a rectangle whose area increases

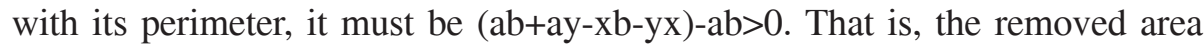
"xb" must always be smaller than the added area "ay-xy". So, the area of final rectangle can always be greater than the first one.

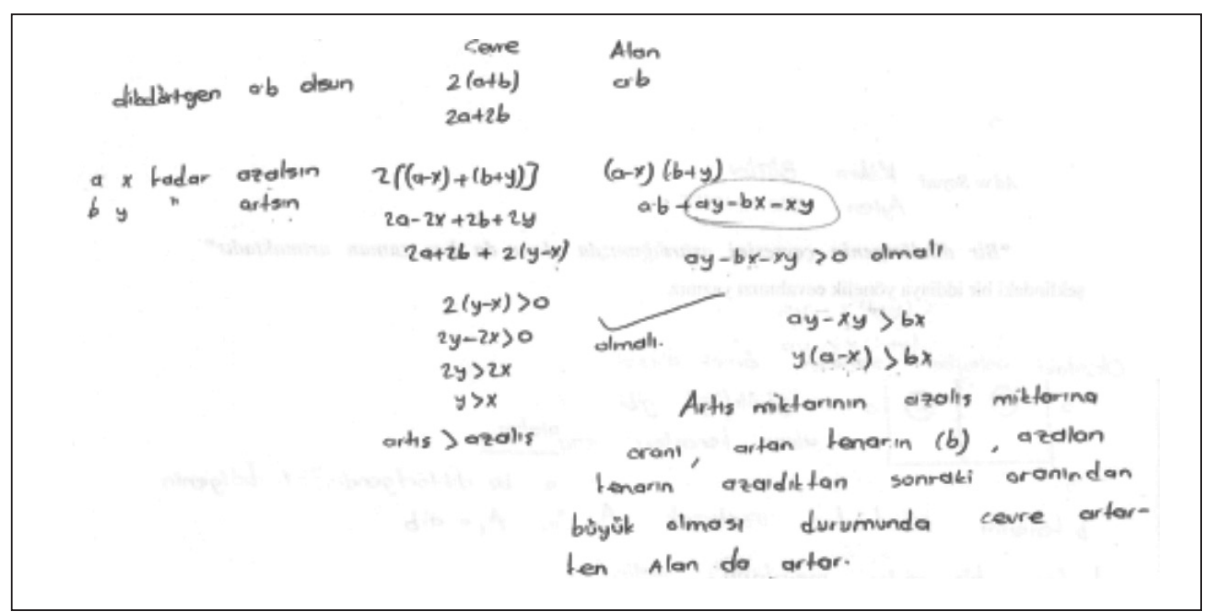

Figure 8 - Proof of $\mathrm{G}^{3}$

A1: Is there anyone who found a counter-example for the last proof of G2? So, what is the last form of our conjecture "if we increase the perimeter of a rectangle, the area increases, as well"

\footnotetext{
${ }^{3}$ The translation of the descriptive sentence in Figure 8 from Turkish is "The ratio of increased quantity to decreased quantity, if the ratio of increased length (b) is greater than the decreased length after it has decreased, the perimeter increased the area increased."
} 
G2: We have three cases for our conjecture:

First case: The increase of both sides of a rectangle.

Second case: While the width or length of one side remains the same, the other one increases.

Third case: On the condition that the amount of increase is greater than decrease. The multiplication of $x / y$ and the length of decreased side should be longer than the final rectangle's increased side. Where the amount of increase is called as " $x$ " and the amount of decrease is called as " $y$." In this case, when the perimeter increases, the area increases, too.

The accuracy of the last proof is provided by G1 and G6's proof given at the beginning and improved proof towards G2 and G7's counter-examples. We can say that it is a result of proof-analysis which is different from exceptionbarring, because our primitive conjecture changes as in exception-barring. Yet, G2 changed the conjecture as the first steps of proof and the direction of their and G7's counter-examples. And, it shows that the proof is working for the new conjecture.

\section{Discussion and conclusion}

The pre-service teachers studied using a conjecture, proved it, tested their proofs, suggested definitions, created counterexamples, made mistakes and generalized conjectures; soon, they completed the steps of forming mathematical knowledge as suggested by Lakatos's assertions concerning the formalization of mathematics knowledge. Toumasis (1997) explained that NCTM standards suggest an environment in which students reason mathematically, communicate mathematically, and make mathematical connections. Therefore, it is observed that there are many similarities between the environment proposed by NCTM standards and the environment prepared according to Lakatos's model. Moreover, Atkins (1997) explained that in Lakatos' environment, students can express their feelings, discuss their opinions and argue with the teacher and peers about their views. In this study, pre-service teachers discussed the relation between perimeter and area of a rectangle. They proved the conjecture, refuted it and discussed their proofs, opinions and examples with teachers and peers. Thus, Lakatos' method engages pre-service teachers in presenting mathematical discussions and testing the validity of those discussions in a social setting.

Lakatos' method gives the students the opportunity to improve their knowledge by using an inductive method instead of the deductive method 
(SRIRAMAN, 2003). While pre-service teachers were improving the primitive conjecture, they found proofs, counter-examples, lemmas and definitions and combined them during the process of proof-analysis. That is, they tried to create a whole with the individual pieces.

Counterexamples can be used to help students develop their mathematical reasoning (BOATS et al., 2003). In this study, pre-service teachers examined area and perimeter of a rectangle. The perimeter and area of a figure are two different measures. Using counter-examples, they created new conjectures and definitions for two different concepts and identified the possible relationships between them. Because of the counter-examples, pre-service teachers believed that the conjecture was not correct. Similarly, Ma (1999) explained that some teachers used counter-examples to show students the conjecture is not correct. Unlike the Lakatos' method, pre-service teachers did not attempt to bar the examples. One of the reasons for this can be that they are not accustomed to be in such situations (LARSEN; ZANDIEH, 2008). The authority of traditional school mathematics prevents pre-service teachers from rejecting these counterexamples. In this context, it is said that the steps of Lakatos' method cannot be carried out in a real classroom.

In Atkins (1997), Reid (2002) and Yim et al. (2008), the method of monster-barring and the method of exception-barring were observed among elementary students. In this study, the method of monster-barring and the exception-barring were also observed. Yet, the pre-service teachers first rejected the primitive conjecture and then, with the help of the teacher, some groups attempted to develop the conjectures that comprised counter-examples. In the last, they improved the conjecture within the scope of counter-examples and proofs. This process reflects the pre-service teachers' thought-experiments in the cycling of conjecture-proof-refutation.

Proof has a vital role in the proof-analysis which aims to make the proof with resulting modification to the conjecture rather than simply exclude the counter-example from the conjecture (LARSEN; ZANDIEH, 2008). Unlike some studies such as Yim et al. (2008), in this study the proof-analysis was observed.

The finding shows that some pre-service teachers did not continue to develop the conjecture and stopped the monster-barring stage. Those pre-service teachers had an understanding that if the perimeter increases, the area increases, as well. The reason for this understanding is that pre-service teachers focused only on the increasing the sides. Ma (1999) explained that some teachers had 
the same understanding about the perimeter and area of a figure. Ma connected this understanding to the teachers' own content and pedagogical content knowledge. In this context, researchers using the process of proofs and refutation should have enough knowledge about the subject.

\section{Educational implication}

A learning environment designed based on Lakatos' method provides us important information about the process of changing and developing mathematical knowledge. In the traditional mathematical teaching, results are given more importance than the formation process of knowledge. However, determining the formation process of mathematical knowledge can help us to inform what happened and how such knowledge was obtained. Besides, such activities reveal the importance of counter-examples in the development of mathematical knowledge.

In an environment based on Lakatos' method, pre-service teachers experienced the production of mathematical knowledge without using a book or an expert (authority). In this context, it is considered that this method can be used as a teaching approach. In addition, taking into consideration their views, pre-service teachers had the opportunity to examine their conjecture and proofs in an environment having no right or wrong answers and no winners or losers. In this state, environments that allow meaningful learning shall be designed.

\section{References}

ATKINS, S. L. Lakatos' Proofs and Refutations comes alive in an elementary classroom. School Science and Mathematics, Corvallis, v. 97, n. 3, p. 150-154, Mar. 1997.

BOATS, J. J. et al. Geometric conjectures: The importance of counterexamples.

Mathematics Teaching in the Middle School, Reston, v. 9, n. 4, p. 210-215, Dec. 2003.

DAVIS, P. J.; HERSH, R. The Mathematical Experience. Harmondsworth: Penguin, 1980.

ERNEST, P. The Philosophy of Mathematics Education. London: The Falmer Press, 1991. 
FREUDENTHAL, H. Mathematics as an Educational Task. Dordrecht: Reidel, 1973.

FUJITA,T.et al. Proofs and refutations in lower secondary school geometry. 2011.

Available at: <http://www.cerme7.univ.rzeszow.pl/> Accessed at: Jan. 2012.

GRAVEMEIJER, K.P.E. Developing Realistic Mathematics Education. Culenborg, Technipress, 1994.

LAKATOS, I. Proofs and Refutations: The logic of Mathematics discovery.

Cambridge: Cambridge University Press, 1976.

LARSEN, S.; ZANDIEH, M. Proofs and refutations in the undergraduate mathematics classroom. Educational Studies in Mathematics, Dordrecht, v. 67, n. 3, p. 205-216, Mar. 2008.

MA, L. Knowing and teaching elementary mathematics: Teachers' understanding of fundamental mathematics in China and the United States. Mahwah: Lawrence Erlbaum Associates Press, 1999.

REICHEL, H. C. Lakatos and aspects of mathematics education. In: KAMPIS, G.; KVASZ, L.; STÖLTZNER, M. (Ed.). Appraising Lakatos: Mathematics, methodology and the man. Dordrecht: Kluwer Academic Publishers, 2002. p. 255-260.

REID, D. Conjectures and refutations in grade 5 mathematics. Journal for Research in Mathematics Education, Reston, v. 33, n. 1, p. 5-29, Jan. 2002.

SRIRAMAN, B. Can mathematical discovery fill the existential void? The use of Conjecture, Proof and Refutation in a high school classroom. Mathematics in School, Leicester, v. 32, n. 2, p. 2-6, Mar. 2003

SRIRAMAN, B. An Ode to Imre Lakatos: Quasi-thought experiments to bridge the Ideal and actual mathematics classrooms. Interchange, Dordrecht, v. 37, n. 1-2, p. 151178, Apr. 2006.

STEINER, H. G. Philosophical and Epistemological Aspects of Mathematics and their Interaction with Theory and Practice in Mathematics Education. For the Learning of Mathematics, Kingston, v. 7, n. 1, p. 7-13, Feb. 1987.

SWINYARD, C.; LARSEN, S. Proofs and refutations as a model for defining limit. In: ANNUALCONFERENCE ON RESEARCH IN UNDERGRADUATE MATHEMATICS EDUCATION, $13^{\text {th }}, 2010$, Raleigh, NC. Proceedings... Raleigh, North Carolina: RUME, 2010. p. 1-12. Available at: <http://sigmaa.maa.org/rume/crume2010/>. Accessed at: Nov. 2011. 
THOM, R. Modern Mathematics: Does it Exist? In: HOWSON, A. G. (Ed.).

Developments in Mathematics Education. Cambridge: Cambridge University Press, 1973. p. 194-209.

TOUMASIS, C. The NCTM standards and the philosophy of mathematics. Studies in Philosophy and Education, Dordrecht, v. 16, n. 3, p. 317-330, July 1997.

YIM, J. et al. The mathematically gifted elementary students' revisiting of Euler's polyhedron theorem. The Montana Mathematics Enthusiast, Montana, v. 5, n. 1, p. 125-142, Jan. 2008.

Submetido em Abril de 2012. Aprovado em Julho de 2012. 